\title{
Leucemia mielóide aguda Ph1-positivo de novo ou crise blástica de leucemia mielóide crônica? Análise molecular e evolução clínica de um caso
}

\author{
G.W.B. Colleoni, M. Satake , C.L. Borovik, J . Kerbauy, M. Yamamoto \\ Serviço de Hematologia Clínica do Hospital do Servidor Público Estadual “Francisco Morato de Oliveira” (HSPE), São Paulo, SP.
}

\begin{abstract}
RESUMO - Os autores relatam um caso de leucemia mielóide aguda (LMA) que apresentava, ao diagnóstico, basofilia no sangue periférico e cariótipo com presença do cromossomo Filadélfia (Ph1). Após um ano de tratamento com quimioterapia intensiva e em fase de remissão clínica e hematológica, a análise molecular pela técnica da reação em cadeia da polimerase-transcriptase reversa (RT-PCR) revelou presença de doença residual (rearranjo b2-a2). A seguir, o paciente apresentou primeira recidiva como LMA e, após a re-
\end{abstract}

\section{NTRODUÇÃO}

A leucemia mielóide crônica (LMC) foi a primeira doença neoplásica associada a alteração cromossômica específica, conhecida como cromossomo Filadélfia (Ph1)․․ E m 1973, Rowley² descreveu que o cromossomo Ph1, ou 22q-, resultava da translocação recíproca e balanceada entre os cromossomos 9 e 22 . A resultante mol ecular dessa transl ocação é a formação de um gene híbrido bcr-abl, envolvendo o proto-oncogene c-abl do cromossomo 9 e a região bcr (ou M-BCR) do cromossomo $22^{3}$. A LMC apresenta curso trifásico: fase crônica, com duração média de 3,5 anos, fase acelerada e crise blástica (linfóide ou mielóide), esta última pouco responsiva à quimioterapia convencional ${ }^{4}$.

A presença do cromossomo Ph1 em pacientes com LMA é fenômeno raro, sendo descrita em apenas $2 \%$ dos $\operatorname{casos}^{5}$. Em geral, estão associados aos subtipos $F A B M 1$ e $M 2^{6,7}$.

$\mathrm{Na}$ LMA, podem ocorrer dois tipos de rearranjo bcr-abl: o primeiro com envolvimento da região $M-B C R$ e idêntico ao encontrado na LMC, podendo ser do tipo b3-a2 ou b2-a2 (com ou sem o exon b3), ambos levando à expressão da proteína p210, com intensa atividade tirosina quinase; o segundo envolvendo o primeiro intron do gene BCR ou região $\mathrm{m}-\mathrm{BCR}$, com expressão da $\mathrm{p} 190^{5}$. Os rearranjos que codificam p210 tornam a LMA indistinguível da missão, evoluiu com quadro hematológico sugestivo de leucemia mielóide crônica (LMC) em fase crônica. Após dez meses, apresentou nova recidiva da LMA. Os autores discutem a dificuldade do diagnóstico diferencial entre LMA Ph1-positivo de novo e crise blástica mielóide como primeira manifestação clínica da LMC, baseados nos aspectos clínicos e moleculares.

UNITERMOS: Leucemia mielóide aguda. Cromossomo Filadélfia. Rearranjo bcr-abl.

LMC em crise blástica mi elóide, enquanto a expressão da p190 identifica a verdadeira LMA, também chamada LMA de novo 5 .

\section{RELATO DO CASO}

J .L.F., masculino, 39 anos, negro, solteiro, escrivão, natural e procedente de Piquete (São Paulo), encaminhado ao Hospital do Servidor Público Estadual em maio de 1993 com história de fraqueza, vômitos pós-alimentares, dor em cólica no hipocôndrio esquerdo e emagrecimento de $13 \mathrm{~kg}$ nos últimos dois meses. Ao exame físico apresentava-se em regular estado geral, descorado +++ l +++ , anictérico, febril, ausência de adenomegalia periférica, visceromegalia ou sufusões hemorrágicas em pele e mucosas. O fundo de ol ho demonstrou presença de áreas de hemorragia retiniana. O hemograma apresentava: $\mathrm{Hb}: 6,1 \mathrm{~g} / \mathrm{dL}$, Htc: $18 \%$, GB: $528.000 / \mathrm{mm}^{3}$ (com $90 \%$ de blastos, $3 \%$ de bastonetes, $4 \%$ de segmentados, $1 \%$ de basófilos e $2 \%$ de linfócitos), plaquetas: $122.000 /$ $\mathrm{mm}^{3}$. O aspirado de medula óssea foi seco, sendo feito o diagnóstico de LMA pel o sangue periférico. A citoquímica revelou positividade à peroxidase e negro de Sudan na maioria dos blastos e a imunofenotipagem mostrou positividade ao CD 13 (35\%) e CD 33 ( $72 \%$ fraco), e os marcadores para linhagens monocítica, megacariocítica e linfói de foram negativos. O cariótipo demonstrou presença do 


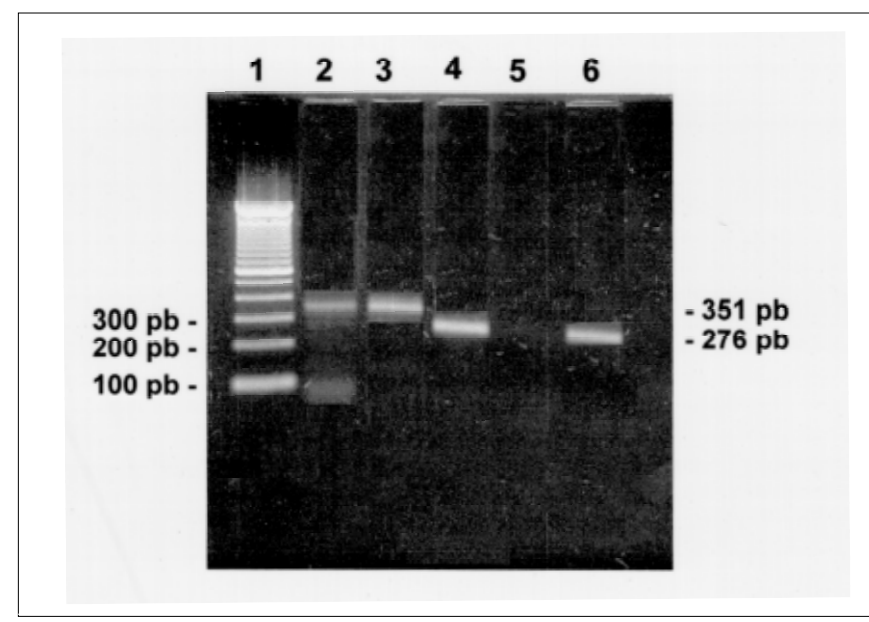

Fig. - El etroforese em gel de agarose 1,5\% corada com brometo de etídio mostrando: 1) marcador Ladder 100; 2) e 3) paci entes com LMC e rearranjo b3-a2 (351 pb); 4) paciente com LMC e rearranjo b2-a2 (276 pb); 5) controle negativo; 6) paciente com LMA Ph1-positivo com o rearranjo b2-a2 (banda 276 pb).

Tabela - Evolução do hemograma durante o período que antecedeu a segunda recidiva (em uso de hidroxiuréia ou citosina arabinosídeo + alfa-interferon). $\mathrm{Hb}$ - hemoglobina (g/dL); Htc - hematócrito (\%); GB - glóbulos brancos e plaquetas $\left(/ \mathrm{mm}^{3}\right)$

\begin{tabular}{|c|c|c|c|c|c|}
\hline Data & $\mathrm{Hb}$ & Htc & GB & Diferencial & Plaquetas \\
\hline Out/94 & 10,5 & 30,4 & 4970 & $(1-10-0-6-41-0-1-35-6)$ & 36.000 \\
\hline Dez/95 & 10,7 & 30,2 & 8444 & $(1-4-15-7-26-10-2-5-29-1)$ & 58.000 \\
\hline Mar/95 & 9,6 & 29,8 & 34360 & $(7-7-34-10-2-9-2-7-21-1)$ & 63.000 \\
\hline Abr/95 & 8,2 & 25,6 & 11100 & $(1-14-2-4-14-0-4-61-0)$ & 48.000 \\
\hline Mai/95 & 8,8 & 26,4 & 174000 & $(22-60-5-0-0-2-2-3-4-2)$ & 81.000 \\
\hline
\end{tabular}

cromossomo Ph1 - 46, XY, t(9; 22). O paciente foi submetido à leucoaférese e indução com daunorrubicina $\left(45 \mathrm{mg} / \mathrm{m}^{2}\right.$ por 3 dias) e citosina arabinosídeo $\left(200 \mathrm{mg} / \mathrm{m}^{2}\right.$ por 7 dias). Apresentou remissão hematológica, recebendo consolidação com as mesmas drogas e doses nos meses de jul ho e setembro de 1993. Não possuía doador HLA compatível para TMO alogênico. Em novembro de 1993, foi submetido à intensificação com citosina do arabi nosídeo $3 \mathrm{~g} / \mathrm{m}^{2}, 12 / 12$ horas por 4 dias e daunorrubicina $\left(40 \mathrm{mg} / \mathrm{m}^{2}\right.$ nos dias 5, 6 e 7). Em maio de 1994, a pesquisa do rearranjo bcr-abl (pela técnica do P(R) a partir de aspirado de medula óssea foi positiva para o rearranjo do tipo b2-a2 (fig. acima).

O paciente permaneceu em remissão clínica e hematológica por um ano. Em junho de 1994, apresentou recaída como LMA-M2, sendo tratado com o mesmo esquema utilizado na primeira indução. Após a quimioterapia, o aspirado de medula óssea demonstrou $7,6 \%$ de blastos e o paciente desenvolveu leucocitose (em torno de $90.000 / \mathrm{mm}^{3}$ ) com desvio à esquer da até blastos. A fosfatase alcalina dos neutrófilos teve escore de 14 (normal: 15-75). O controle da leucometria foi realizado com hidroxiuréia e esta se manteve ao redor de $30.000 / \mathrm{mm}^{3}$, com escalonamento até blastos, e cerca de $5 \%$ de basófilos (tabela). Em nenhum momento foi detectado aumento do fígado ou baço, quer pelo exame físico ou por ultrasonografia abdominal. Em outubro de 1994, foi submetido a esquema com citosina arabinosídeo $15 \mathrm{mg} / \mathrm{m}^{2} \mathrm{sc} / 14$ dias e alfa interferon 3 milhões de unidades $\mathrm{sc} / \mathrm{dia} / 14$ dias, com controle da leucocitose (Hb: 10,5g/dL, Htc: $30,4 \%$, GB: $4.970 / \mathrm{mm}^{3}$, sendo $1 \%$ de promielócitos, $10 \%$ de mi elócitos, $0 \%$ de metamielócito, $6 \%$ de bastonetes, $41 \%$ de segmentados, $0 \%$ de eosinófilo, $1 \%$ de basófilos, $35 \%$ de linfócitos e $6 \%$ de monócitos e 36.000 plaquetas $/ \mathrm{mm}^{3}$ (tabela). E m maio de 1995, apresentou a segunda recidiva da LMA-M $2(87,5 \%$ de blastos mielóides na medula óssea), sem resposta à quimi oterapia, evoluindo com insuficiência respiratória e óbito em 25/5/1995.

\section{DISCUSSÃO}

O tipo do rearranjo molecular nas leucemias Ph1-positivo pode sugerir a origem da LMA: a presença do rearranjo que codifica a p190 é característico de LMA de novo, enquanto os casos que apresentam o rearranjo que codifica p210 podem corresponder à LMA de novo ou à crise blástica mielóide de LMC, até então não diagnosticada. $\mathrm{Na}$ segunda situação, a evolução clíni ca pode determinar a verdadeira natureza da leucemia.

A proximadamente, $6 \%$ das LMCS apresentam a crise blásti ca como primeira mani festação clínica8. No caso em questão, é provável que tenha ocorrido crise blástica mielóide de LMC como primeira manifestação da doença, sendo esta indistinguível da LMA-M 2 quando se utilizam apenas critérios morfológicos e imunológicos. Essa hipótese é reforçada pela presença de intensa leucocitose e desvio à esquerda com predomínio de blastos e escore de fosfatase alcalina de neutrófilos no limite inferior da normalidade, após o tratamento da primeira recidiva. Porém, a ausência de esplenomegalia em todas as fases de evol ução deste caso não é compatível com a grande maioria dos casos de LMC em crise blástica.

A análise molecular pela reação em cadeia da polimerase-transcriptase reversa (RT-PCR) ${ }^{9}$, com o achado do rearranjo do ti po b2-a2 que codifica p210, 
não contribuiu para o diagnóstico diferencial entre LMA de novo e crise blástica mielóide de LMC.

Não há dúvidas de que o rearranjo bcr-abl é a base da patogênese da LMC e que outras al terações em outros genes, como a mutação no p53, estariam implicadas na evolução para a fase acelerada e crise blástica ${ }^{10}$. Particularmente nas crises blásticas mielóides, $80 \%$ dos casos apresentam evolução cromossômica clonal como duplicação do Ph1, trissomia do 8, trissomia do 19 , isocromossomo $17 q$, trissomia do 21 e perda do $Y^{11}$. O fato de o nosso paciente apresentar apenas o cromossomo Ph1 como única al teração citogenética ao diagnóstico não confirma nem afasta a hipótese de crise blástica mielóide de LMC.

Cerca de $20 \%$ dos pacientes com LMC em crise blástica mielóide tratados com quimioterapia agressiva passam a apresentar uma hematopoese típica de LMC, com sobrevida média oscilando entre 8 e 10 meses até que sobrevenha nova agudização ${ }^{12}$, enquanto os pacientes que não respondem à quimioterapia têm sobrevida mediana de dois meses ${ }^{12}$. No presente caso, o tratamento agressivo permitiu que o paciente permanecesse em remissão clínica e hematológica por um ano, até a primeira recidiva, e, provavel mente, contribuiu para a sobrevida global de dois anos.

\section{AGRADE CIMENTOS}

Os autores agradecem a llka Maria Manrique de Souza, Ana Patrícia A. Santana e André Luís Tavares, médicos residentes do HSPE, pelo acompanhamento clínico deste paciente.

\section{SUMMARY}

Molecular analysis and clinical evolution of one
case of Ph1-positive acute myeloid leukemia (AML)

A case of AML presented with basophilia in peripheral blood and Ph1 chromosome in karyotype analysis is reported. After one year of treatment with intensive chemoterapy and clinical and hematological remission, molecular analysis (RT-PCR) detected minimal residual disease (b2-a2 rearrangement). Thus, the patient rel apsed as AML and, after second remission, he devel oped a hematological picture of chronic CML. Ten months later, he relapsed again as AML. The difficulties of diagnosis between AML Ph1-positive de novo and myel oid blast crisis of CML, as the first manifestation of disease, based on clinical and molecular aspects are discussed. [Rev Ass Med Brasil 1998; 44(3):253-5.]

KEY WORDS: Acute myeloid leukemia. Philadel phia chromosome. bcr-abl rearrangement.

\section{REFERÊ NCIAS BIBLIOGRÁFICAS}

1. Nowell PC, Hungerford DA. A minute chromosome in human chronic granulocytic leukemia. Science 1960; 132: 1.497.

2. Rowley J D. A new consistent chromosomal abnormality in chronic myelogenous leukaemia identified by quinacrine fluorescence and Giemsa staining. Nature 1973; 243: 290-3.

3. de Klein A, van Kessel AG, Grosveld G et al. A cellular oncogene is translocated to the Philadel phia chromosome in chronic myel ocytic leukemia. Nature 1982; 300: 765-7.

4. Champlin RE, Golde DW. Chronic myelogenous leukemia: recent advances. Blood 1985; 65: 1.039-47.

5. Kurzrock R, Gutterman J U, Talpaz M. Themolecular genetics of Philadelphia chromosome-positive leukemias. N Engl J Med 1988; 319: 990-8.

6. Bennett J M, Catovsky D, Daniel MT et al. Proposed revised criteria for the classification of acute myeloid leukemia: a report of the French-American-British Cooperative Group. Ann Intern Med 1985; 103: 626-9.

7. Cigudosa J C, Almeida MTA, Carrasco $V$ et al. BCR-ABL rearrangement and "variant" $P$ hiladel phia chromosome in de novo acute myelogenous leukemia $F A B$ subtype $M 1$. Br J Haematol 1995; 91: 932-4.

8. Cervantes F, Rozman C, Ballesta F et al. Leucemia mieloide crónica. Descripción de una serie de 207 casos. Sangre 1983; 28: 140-50.

9. Roth MS, Antin J H, Bingham EL, Ginsburg D. Detection of Philadel phia chromosome-positive cells by the polymerase chain reaction following bone marrow transplant for chronic myel ogenous leukemia. Blood 1989; 74:882-885.

10. Nakai H, Misawa S, Toguchida J, Yandell DW, Ishizaki K. Frequent p53 gene mutations in blast crisis of chronic myelogenous leukemia, especially in myel oid crisis harboring loss of chromosome 17p. Cancer Res 1992; 52:6.588-93.

11. Bernstein R, Gale RP. Do chromosome abnormalities determine the type of acute leukemia that develops CML ? Leukemia 1990; 4: 65-8.

12. Canellos GP. The treatment of chronic granulocytic leukaemia. Clin Haematol 1977; 6: 113-28.

13. Savage DG, Goldman J M. Approaches to the treatment of chronic myeloid leukemia. Int J Hematol 1994; 60: 1-21. 